\title{
PROFESSIONELE GEHEIMHOUDING
}

\author{
HC Buckle, L Lundie en I Treadwell
}

\section{OPSOMMING}

Aangesien professionele geheimhouding 'n "sensitiewe" onderwerp is wat aan alle verpleegkundige bekend behoort te wees, is daar besluit om die persepsie daarvan by student verpleegkundiges te bepaal. Tydens die navorsingsprojek is verskeie verrassende afleidings gemaak wat dui op leemtes in opleiding of indiensopleiding van die verpleegpersoneel. Die leemtes het hoofsaaklik ontstaan a.g.v. die ontwikkeling in die mediese en tegnologiese velde. Hierdie vooruitgang noodsaak die hersien of opstel van riglyne vir professionele geheimhouding sodat die verpleegkundige verseker is van korrekte optrede.

\section{SUMMARY}

Confidentiality is a "sensitive" subject known to all professional nursing personnel. The perception of confidentiality in nursing students was determined during a research project. Some responses were surprising. The surprises were mostly due to the fast development in the medical and technology fields. These findings proved to be of significance in that guidelines for confidentiality are not up to date with the developments in these fields. These guidelines should be revised or rewritten to bring them up to date and help the professional nurse in decisions on aspects conceming confidentiality.

\section{TITEL}

Studentverpleegkundiges se persepsie van professionele geheimhouding.

\section{MOTIVERING}

Die verpleegberoep lewer 'n diens aan die samelewing wat die welsyn van die individu of samelewing te alle tye op die hart moet dra (Searle \& Pera, 1993:5). Daar kan van die veronderstelling uitgegaan word dat daar met "welsyn" nie alleen verwys word na fisiese, psigiese en emosionele welstand van die hulpbehoewende nie, maar ook na die behoefte en die reg op privaatheid en konfidensialiteit. Privaatheid impliseer die reg om vry te wees van ongewensde en onredelike publisiteit, terwyl konfidensialiteit nou verwant is aan eersgenoemde en ' $n$ vertrouensverhouding impliseer waarbinne een party (die pasiënt) met 'n ander (die verpleegkundige) sensitiewe inligting deel en verwag dat laasgenoemde dit nie bekend sal maak nie (Brent, 1990:6).

Vanweë die aard van hul beroep bevind die verpleegkundige hom/haar deurlopend in 'n vertrouensverhouding met die pasiënt, wat gekenmerk word aan professionaliteit en wedersydse vertroue (Brent, 1990:6). Binne hierdie milieu van vertroue word sensitiewe inligting dikwels aan die verpleegkundige bekend gemaak en wel binne die raamwerk van konfidensialiteit, wat algemeen bekend staan as professionele geheimhouding.

Professionele geheimhouding is onderhewig aan bepaalde riglyne en beginsels van die professionele praktyk. Hierdeur word die integriteit van die verpleegkundige beheer deur die afdwing van 'n etiese kode deur die norme van gelykes en samelewing (Searle \& Pera, 1993:5). Die studentverpleegkundige behoort tydens sy/haar teoretiese en kliniese opleiding toenemend vertroud te raak met die beginsels van professionele geheimhouding. Verpleegkundiges word aanspreeklik gehou vir hul optredes en is verantwoordbaar ten opsigte van die Wet op Verpleging (Wet 50 van 1978) sowel as die professionele beheerliggaam, naamlik die Suid-Afrikaanse Raad op Verpleging (Searle \& Pera, 1993:5). Die versuim om konfidensialiteit te bewaar impliseer skending van professionele geheimhouding.

In die verband identifiseer Mortlock (1994:42-45) verskeie potensiële areas binne die praktyk, wat aanleidend kan wees tot die skending van professionele geheimhouding naamlik:

- besprekings by die bed van 'n pasiènt
- 'n telefoon vir amptelike gebruik wat foutief in ' $n$ publieke area geinstalleer is

- gesprekke aangaande verbruikers (familie, gesin ens) in openbare areas (ontvangslokale, gange, teekamers ens.)

- die verskaffing van inligting telefonies waartydens positiewe identifisering van persoon wat navraag doen nie moontlik is nie.

Vanuit hierdie perspektief is dit noodsaaklik om die persepsies van die studentverpleegkundiges ten opsigte van geheimhouding te bepaal.

\section{DOELSTELLING}

Die doel van die studie was om die persepsies van die vierde jaar studentverpleegkundiges ten opsigte van professionele geheimhouding en die toepassing van beginsels van geheimhouding in die praktyk te bepaal.

Ten einde die doel te verwesenlik is probleemsituasies en beginsels ten opsigte van professionele geheimhouding vanuit die literatuur geidentifiseer. Studentverpleegkundiges se persepsie ten opsigte van geïdentifiseerde situasies is vervolgens bepaal sowel as hulle ervaring van die toepassing van die beginsels van professionele geheimhouding in die praktyk.

\section{OPERASIONELE DEFINISIES}

\section{PROFESSIONELE} GEHEIMHOUDING

Die bewaring van inligting wat een persoon met 'n ander persoon binne professionele praktykverband deel en wel binne die grense van konfidensialiteit.

\section{STUDENT}

Die student is ' $n$ persoon wat by die Suid Afrikaanse Raad op Verpleging as 'n student geregistreer is en tans in sy/haar finale jaar van opleiding is.

\section{a PERSEPSIE}

Die vertolking of siening van studentverpleegkundiges met betrekking tot professionele geheimhouding.

\section{NAVORSINGSONTWERP}

'n Beskrywende opname studie is gedoen met vraagstelling wat gegrond is op resente literatuur as navorsingstegniek. Die vraelys 


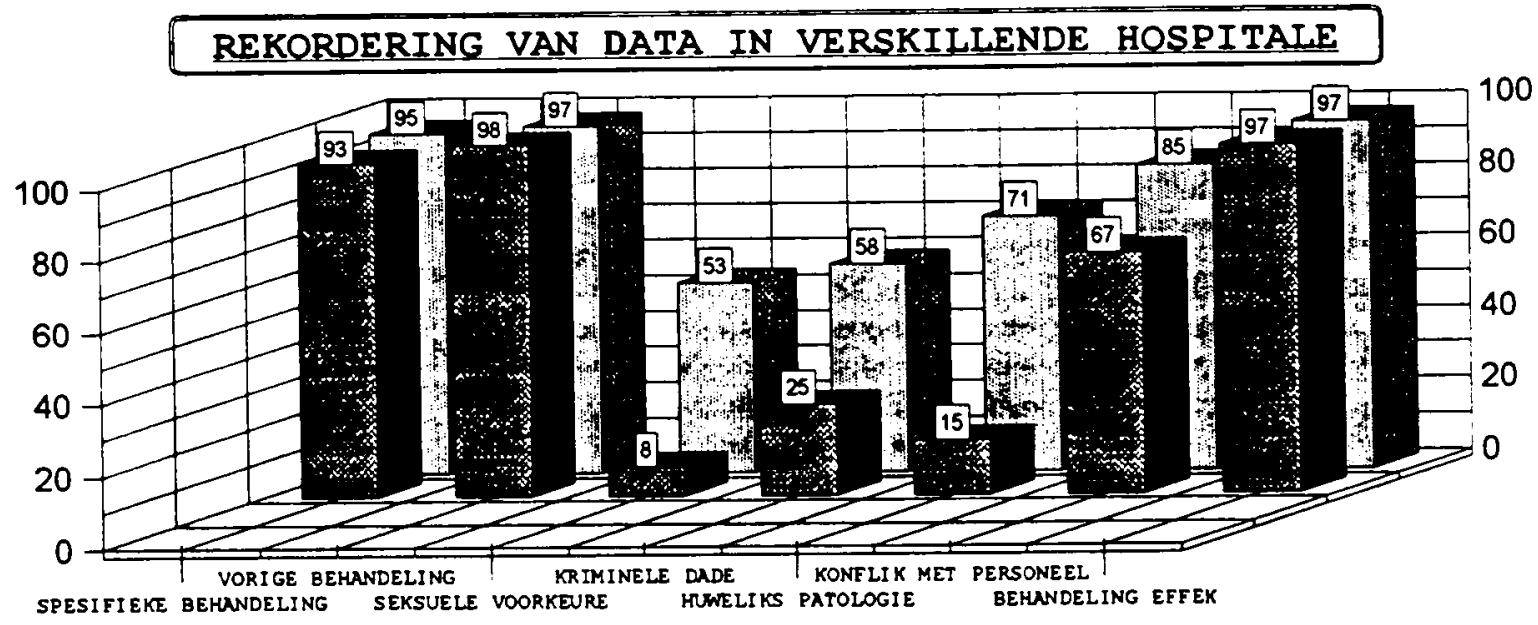

PSIGIATRIESE HOSPITAAL (Y1)

ALGEMENE HOSPITAAL (Y2)

handel in hooftrekke oor mededeling van inligting, mediese rekords, wetlike aspekte, navorsing, nuwe tegnologie, genetika en ander. Die inhoud van die vrae word saam met die data analise beskryf.

'n Vraelys is vervolgens voltooi deur 25 verpleegkundiges wat nie deel gevorm het van die steekproef nie. Na afloop is van die vrae herstruktureer om die duidelikheid en verstaanbaarheid te verseker en waninterpretasie tot die minimum te beperk.

Die geldigheid is bepaal deur die voorlegging van die vraelys aan ' $n$ fokus groep wat die sigwaarde, nuansering en balans asook inhoudsgeldigheid van die vraelys geëvalueer het. Daar is bevind dat die vraelys veral voldoen het aan die aspek van omvattendheid.

\section{STEEKPROEF}

'n Toevalige seleksie is gedoen uit al die finale jaar verpleegstudente aan een universiteit en een verpleegkollege in die Gauteng provinsie. Drie-en-dertig (60\%) van die 55 universiteitstudente en 29 (85\%) van die 34 studente van die verpleegkollege het die vraelys terug besorg. Die getal respondente is dus 62 en die respons $69,7 \%$. Die populasie is dus 89 (N89) en die steekproef (n62).

\section{BEPERKINGE}

- Die steekproef is slegs geloots aan cen universiteit en een verpleegkollege in die Gauteng provinsie en slegs vierde jaar studenteverpleegkundige is in die steekproef ingesluit.

- Die vraelys was voorgelê aan fokusgroep wat reeds professioneel opgelei is. Hierdie groep het die vrae korrek geïnterpreteer aan die hand van die spesifieke situasies wat geskep is. Dit het egter geblyk asof die studentverpleegkundiges tog probleme ervaar het om die vrae korrek te interpreteer wat moontlik 'n gevolg kan wees van hul eng en spesifiek gerigte beskouing aangaande professionele geheimhouding.

- Ten spyte van 'n beroep op die respondente om die vrae eerlik te beantwoord. het sommige van die antwoorde twyfel laat ontstaan of die respondente ten volle eerlik was. Uit die antwoorde wat ontvang is het dit geblyk dat die keuse van Onseker ook gebied moes word in plaas van slegs Ja of Nee.

\section{DATA-ANALISE}

Die data word in sewe hoofgroepe aangebied.

\section{MEDEDELING VAN}

\section{VERTROULIKE INLIGTING.}

Hierdie afdeling sluit vrae in ten opsigte van mededeling van inligting aangaande pasiënte asook personeel.

Die respondente was dit eens dat alle personeel in ' $n$ afdeling waar 'n HIV positiewe pasiënt verpleeg word, daarvan kennis moet dra. Volgens Cameron, (nd:81) rasionaliseer gesondheidswerkers dat verminderde geheimhouding van HIV pasiënte genoodsaak word vanweë die hoë risiko waaraan werkers blootgestel is. Die bevindinge van 'n hofsaak oor HIV konfidensialiteit was, dat alhoewel HIV hoogs aansteeklik is, dit minder aansteeklik is as baie ander infektiewe toestande. Die metode van oordraagbaarheid volg ' $n$ duidelik gedefinieerde patroon. Alhoewel die gesondheidspersoneel blootgestel is, was daar tot op hede in Suid Afrika nog nie cen positief bevestigde geval a.g.v. versorging van HIV positiewe pasiënte nie. Die risiko word dus as minimaal gereken Die gewone infeksie beheermaatreels behoor genoegsame voorsorg te wees. Personeel hoef dus nie spesifiek ingelig te word to.v. ' $n$ HIV pasient nie.

Met betrekking tot inligting wat as baie sensitief beskou word as gevolg van die wetlike implikasies daarvan, sou die meerderheid respondente die inligting bekend maak aan die psigiater ( $85 \%$ ) en maatskaplike werker $(78 \%)$.

Die respondente sou konfidensiële inligting aangaande pasiënte en hul diagnoses hoofsaaklik op aanvraag aan ander geneeshere verskaf $(62 \%)$, mediese skemas $(27 \%)$ en versekeringsmaatskappye $(17 \%)$. Die algemene mening is dat wat deur ' $n$ studentverpleegkundige aangaande haar geestestoestand (selfmoordgedagtes) aan 'n professionele verpleegkundige meegedeel is aan die studenteberader bekend gemaak moet word. Dit stem ooreen met Carlisle (1991:46).

\section{TOEGANG TOT MEDIESE REKORDS.}

Die vrae in hierdie afdeling het hoofsaaklik gesentreer rondom die reg van toegang en insae in mediese rekords asook die rekordering van die relevante inligting in pasiënterekords. Naish en Barr (1991:3003-3001) se artikel verskaf leiding oor hierdie aspekte.

Met betrekking tot toegang en insae in die mediese rekords, is $100 \%$ van die respondente van mening dat die geneesheer volle toegang mag hê, terwyl $87 \%$ van die respondente adminstratiewe personeel toegang tot konfidensiële dele van rekords sou weier. Geen toegang tot rekords sou aan navorsers buite die mediese veld verleen word nie.

Ten opsigte van insae van pasiènte in hul eie mediese rekords voel $74 \%$ van die respondente dat pasiènte die reg daartoe het en $62 \%$ is van mening dat kinders onder 16 jaar wel toegang tot hulle mediese rekords mag verkry. Navorsers binne die mediese veld sou toegang geweier word deur $46 \%$ van die respondente.

Die rekordering van konfidensiële aspekte in pasiënterekords in 'n psigiatriese afdeling versus ' $n$ algemene afdeling word in figuur 1 uiteen gesit. Die grootste verskil in rekordering van data is gevind t.o.v. seksuele voorkeure ( $8 \%$ toenoor 53\%), kriminele data 
Tabel 1 SITUASIES WAAR INLIGTING BEKEND GEMAAK MAG WORD

Wetlike aspekte
Getuie in hofsaak
Ter verdediging van self in hof
Tydens dissiplinêre stappe van SARV
Statutêre aanmeldbare toestande
In openbare belang

$\%$

97

80

90

90

80 n

61

59

59

61

60
( $25 \%$ teenoor $58 \%$ ) en huwelikspatologie ( $15 \%$ teenoor $71 \%$ ).

\section{WETLIKE ASPEKTE.}

Die vrae in hierdie afdeling sentreer rondom etiesmorele- en wetlik verpligte aspekte met betrekking tot die bekendmaking, beskikbaarstelling of weerhouding van vertroulike inligting.

Die aanmelding van aanmeldbare siektes is volgens $8 \%$ van die respondente skending van professionele geheimhouding. Wetlik word daar voorsiening gemaak vir situasies waarin vertroulike inligting bekend gemaak kan word. ( Brahams, 1991:1277; Die Mediese Vereniging van Suid Afrika, 1993; SARV, 1992). Vanuit die navorsingsresultate word die persepsies van die respondente in dié verband in tabel 1 uiteen gesit.

In gevalle waar pasiënte toegang tot hul mediese rekords verlang word die afleiding gemaak dat dit op skriftelike versoek gedoen word (SARV, 1992). Op skriftelike versoek sou $74 \%$ van die respondente toegang tot rekords verleen het terwyl $63 \%$ dit sou toelaat op mondelik versoek en $49 \%$ het gevoel dat insae ter enige tyd verkry mag word. Ook is $68 \%$ van die respondente van mening dat die geneesheer die reg het om gedeeltes van die mediese rekords, volgens sy mening, van die pasiënt te weerhou. Hierdie persepsie stemooreen met die SARV (1992) ten einde die pasiënt te beskerm.

\section{NAVORSING.}

In hierdie afdeling is die persepsie van die respondente bepaal ten opsigte van die volgende:

- die verskaffing van statistiese nie-identifiserende data van pasiënte aan navorsers soos uiteengesit in figuur 2 , asook

- die verantwoordelikheid van navorsers teenoor deelnemende kliënte.

Met betrekking tot die verantwoordelikheid van die navorser teenoor deelnemende kliënte het die meerderheid konfidensialiteit en privaatheid (95\%) asook anonimiteit (97\%) ondersteun.

Figure 2

\section{GROEPE AAN WIE DATA VERSKAF WORD}

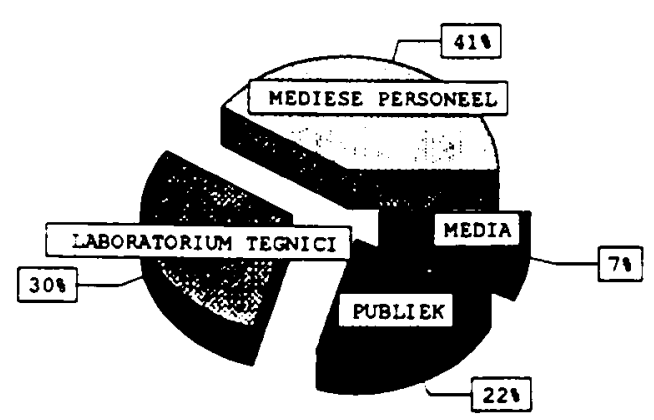

MEDIESE EN VERWANTE BEROEPE

LABORATORIUM TEGNICI

PUBLIEK \& ONDERSTEUNINGSGROEPE MEDIA

\section{PERSONEEL}

Alle administratiewe personee

Alle verpleegkundiges

Alle geneeshere

Alle paramediese personee

Slegs geselekteerde persone

Persone wat direk met pasiēnt werk

\section{Tabel 2 TOEGANG TOT REKENAARDATA}

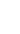

$\begin{array}{rr}\% & \text { n } \\ 13 & 61 \\ 25 & 60 \\ 30 & 60 \\ 18 & 61 \\ 70 & 61 \\ 93 & 61\end{array}$

\section{GENETIKA}

Vrae in hierdie afdeling sentreer rondom die verskaffing van konfidensiële inligting aangaande biologiese ouers en die etiese aspekte met betrekking tot kunsmatige inseminasie. Min riglyne t.o.v. hierdie aspekte bestaan alhoewel daar baie voorstelle is (Gericke, 1995). By inseminasie klinieke teken die ontvanger 'n wetlike dokument waarin hy/sy onderneem om nie die kliniek te dagvaar indien die baba gebore word met 'n genetiese defek nie. Die donateur se gegewens moet ten alle tye beskerm word. Kwalifisering as donateur geskied onder baie streng keuringsmaatreëls. Indien die persoon byvoorbeeld positief getoets is as ' $n$ draer van die kistiese fibrose geen sal so 'n persoon nie

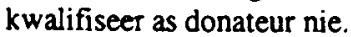

Volgens $72 \%$ van die respondente behoort inligting aangaande biologiese ouers bekend gemaak word aan voornemende aanname-ouers. Met betrekking tot kunsmatige inseminasie is $92 \%$ van die respondente van mening dat daar aangedring mag word op genetiese agtergrond van die donateur terwyl dieselfde vraag, net anders gestel, $59 \%$ van mening is dat die donateur se genetiese agtergrond beskerm moet word.

\section{ANDER}

Die meerderheid van die respondente $(\mathbf{7 5 \%})$ is van mening dat skending van privaatheid kan plaasvind tydens die oorgee van verslag by die bed van die pasiënt $(87 \%)$ asook tydens 'n volbedwas (93\%). Telefoniese gesprekke in die ontvangsarea word deur $93 \%$ as 'n risiko vir skending van professionele geheimhouding beskou. Besprekings in die teekamer lei volgens $95 \%$ van die respondente tot skending van geheimhouding. Hierdie

Hierdie afdeling sentreer hoofsaaklik rondom wat die verkryging en beskikbaarstelling van pasiëntdata toenemend vergemaklik, naamlik op tegnologiese gebied skep egter nuwe kan plaasvind (Faaso,1992:46; Rittman \& Gorman, 1992:14-18). Navorsingresultate in Met betrekking tot telefoniese navrae sou $60 \%$ van die respondente inligtingverskaf het 'n minderheid hul kollegas se huis telefoonnommers $(3 \%)$ of pasiënt diagnoses
$(8 \%)$ sou verskaf of inligting verstrek oor pasiënte wat reeds ontslaan is (10\%).

Ten spyte hiervan is al die respondente $(100 \%)$
bereid om inligting per faksimilie te verskaf. Die oorgrote meerderheid $(98 \%)$ sou die persoon aan wie die faksimilie gerig is, vooraf
in kennis stel en ' $n$ klein persentasie (5\%) sou inligting aan 'n firma rig in plaas van aan 'n persoon. Genesen, Sharp \& Genesen
(1994:1401-1402) verskaf in die artikel oor faksimilië handige riglyne vir die versending van konfidensiële inligting. 
bevindinge stem ooreen met die in die literatuur (Mortlock, 1994:42-45).

Die skokkende bevinding van hierdie navorsingsprojek was dat die respondente (74\%) van mening was dat die beginsels van professionele geheimhouding nie dikwels toegepas word nie. Slegs $26 \%$ meen dat dit dikwels toegepas word.

\section{GEVOLGTREKKINGS.}

Een van die mees verrassende bevindings by die mededeling van inligting was die feit dat die respondente van mening is dat die studentverpleegkundige en stafverpleegkundige $(97 \%)$ ingelig behoort te word van ' $n$ HIV positiewe pasiënt bo die opgeleide verpleegkundige $(95 \%)$ moontlik a.g.v. die meer direkte fisiese kontak wat die persone met die pasiënt het.

Insae tot jou eie medieserekords is 'n aspek wat gelei het tot ambivalensie by die respondente. Die meerderheid $(74 \%)$ is wel van mening dat die pasiënt toegang tot insae mag verkry terwyl die res van mening was dat hulle nie toegang tot die rekords mag verkry nie. Onsekerheid oor watter inligting in watter situasies (psigiatrie of algemene sale) gerekordeer mag word is duidelik uit die response wat verkry is. (Sien figuur 1).

Duidelike wetlike riglyne bestaan wel oor wanneer konfidensiële inligting bekend gemaak kan word, nogtans is daar nog $12.5 \%$ wat onseker is daaroor.

Navorsers gaan skynbaar ' $n$ baie moeilike tyd tegemoet. Die respondente is geensins bereid om verwerkte data beskikbaar te stel aan navorsers nie, ten spyte daarvan dat geen skending plaasvind tydens die bekendmaak van verwerkte data nie.

Die respondente het ook probleme ervaar met aspekte rondom die tegnologie. Alhoewel die meerderheid nie bereid is om telefonies inligting te verskaf nie was $100 \%$ van hulle bereid om konfidensiële inligting per faksimilië te stuur. Rekenarisering van data was ook ' $n$ aspek wat verskeie menings ontlok het.

Genetika speel vandag 'n belangrike rol soos belyk uit die WGO se beklemtoning van die integrasie van genetika in gesondheidsdienste. Hoewel genetika deel is van alle aspekte van verpleging was respondente se begrip oor genetika beperk en onseker. Indien die personeel nie die pasiënt holisties benader nie sal daar baie waardevolle kennis vir die verpleegkundige asook die pasiènt verlore gaan.

Volgens die meerderheid respondente $(\mathbf{7 4 \%})$ word professionele geheimhouding nie dikwels toegepas word nie wat onwillekeurig die vraag laat ontstaan waar die rolmodelle en voorvegters vir die bewaring van professionele geheimhouding is?

\section{AANBEVELINGS.}

Dit is duidelik dat die studentverpleegkundiges se kennis en insig t.o.v. professionele geheimhouding nog besig is om te ontwikkel.

Riglyne wat in die Wet op Verpleging (Wet 50 van 1978) asook die in die Regulasies t.o.v. handelinge en versuime (R866 van 1987) is beperk tot sekere aspekte van professionele geheimhouding, waarvan hoofsaaklik afleidings gemaak moet word. In hierdie verband is daar onder andere ook riglyne beskikbaar met betrekking tot die privaatheid en reg tot vertroulikheid van pasiënte (SARV, 1992). Daar bestaan egter geen riglyne in die Suid Afrikaanse literatuur t.o.v. wettige toegang tot mediese rekords, rekordering van data en nuwe tegnologië soos rekenarisering en faksimilië nie. Daar kan ook van die veronderstelling uit gegaan word, dat interne beleid m.b.t. professionele geheimhouding 'n groot rol kan speel. Enstige oorweging moet geskenk word om riglyne t.o.v. hierdie aspekte op te stel wat kan dien as leiding vir studente sowel as opgeleide personeel.

Die snelle voortuigang op die genetiese gebied, veral neurogenetika, gaan in die toekoms hoër eise aan die verpleegkundige stel. Hierdie aspek noodsaak die insluiting van die beginsels ten opsigte van genetika in die basiese kursus van die studentverpleegkundiges, om laasgenoemde in staat te stel om eties-morele aspekte in die verband te interpreteer.

\section{VERWYSINGS}

BRAHAMS, D. (1991): Medicine and the Law. Medical confidentiality and expert evidence. The Lancet Vol 337: 1276-1277

BRENT, N. J. (1990): Facsimile system revised: focus on confidentiality and privacy. Home Healthcare Nurse Vol 9(6): 6-8.

CAMERON, E. nd: Treating patients with HIV or AIDS: court upholds right to confidentiality and SAMDC, MASA guidlines. Brivate Health Care National Association of Private Hospitals) Vol 4 nd: 79-82

CARLISLE, D. (1991): Accountability: just between you and me. Nursing Times. Vol 87(31): 54-55.

FAAOSO, N. (1992): Automated Patient Care System: The Ethical Impact. Nursing Management Vol 23(7): 46-48

GENESEN, L.,SHARP, H.M. \& GENESEN, M. C. (1994): Faxing Medical Records: Another Threat to Confidetiality in Medicine. IAMA Vol 271(18): 1401-1402
GERICKE, GS. (1995): Persoonlike onderhoud. Departement Mensgenetika. Universiteit van Pretoria.

MEDIESE VERENIGING VAN SUID AFRIKA. (1993): Geneeskundige Praktykbulletin. Regs- etiese vraagstukke. Bylae tot SAMJ Desember 1993

MORTLOCK, T. (1994): Maintaining patient confidetiality in A\&E. Nursing Times Vol 90(34): 42-43

NAISH, J. \& BARR, M. (1991): Right of acces. Health visitor. Vol 64(9): 300-301.

RITTMAN, M.R. \& GORMAN, R.H. (1992): Computerized Databases: Privacy Issues in the Development of the Nursing Minimum Data Set. Computers in Nursing. Vol 10(1): 14:18

SEARLE, C. \& PERA, S. (1993): Professionele praktyk: 'n Suid-Afrikaanse verpleeg-perspektief. 2de uitgawe. Durban: Butterworths.

SUID AFRIKAANSE RAAD OP VERPLEGING. Reëls wat die handelinge en versuime, ten opsigte waarvan die raad tugstappe kan doen, uiteensit. R387 van 15 Februarie 1985 soos gewysig deur R866 van 24 April 1987. Pretoria: Staatsdrukker, 1987

SUID AFRIKAANSE RAAD OP VERPLEGDG.(1992): Beleid oor etiese oorwegings in verpleging. Eerste uitgawe. SARV

WET OP VERPLEGING (1978): (Wet 50 van 1978) en die Wysigings Wet op verpleging, 1981 (Wet 71 van 1981)

H.C. Buckle
Algemene verpleegkunde en
vertoskunde, Ortopediese
verpleegkunde, Psigiatriese
verpleegkunde,
Gemeenskapsgesondheid
verpleegkunde, Verpleegadministrasie.
(Student)
L.Lundie
Algemene verpleegkunde, Verloskunde,
Psigiatriese verpleegkunde,
Gemeenskapsgesondheid
verpleegkunde, Verpleegadministrasie.
(Student)
I. Treadwell
D.Cur DEPARTEMENT
VERPLEEGKUNDE,
UNIVERSITEIT van PRETORIA

